\title{
Determination of Long-Term Creep Properties for 316H Steel Using Short-Term Tests on Pre-strained Material
}

\author{
H. Zhou ${ }^{1} \cdot$ A. Mehmanparast ${ }^{2}$ (I) $\cdot$ K. Nikbin ${ }^{1}$
}

Received: 17 August 2020 / Accepted: 8 December 2020 / Published online: 7 January 2021

(C) The Author(s) 2021

\begin{abstract}
Determination of long-term creep rupture properties for $316 \mathrm{H}$ steel is both costly and time-consuming and given the level of scatter in the data would need substantial number of tests to be performed. The primary objective of this study is to estimate the long-term creep properties of cross-weld (XW) and as-received (AR) $316 \mathrm{H}$ stainless steel by performing accelerated tests on pre-compressed (PC) material. In this work, uniaxial creep rupture tests have been performed on XW specimens and the results have been used to establish a correlation with accelerated test results on the PC material. Moreover, tensile tests have been performed on XW specimens at room temperature and $550{ }^{\circ} \mathrm{C}$ to examine the preconditioning effects on the mechanical response of the material. Similar power-law creep properties have been found for the creep strain rate and rupture time behaviour of the XW and PC specimens. It also has been found that the creep ductility data points obtained from XW and PC specimens fall upon the estimated trend for the AR material at $550{ }^{\circ} \mathrm{C}$ when the data are correlated with the applied stress normalised by $0.2 \%$ proof stress. The results show that the long-term creep properties of the XW and AR material can be estimated in much shorter time scales simply by performing tests on the PC material state.
\end{abstract}

Keywords Creep $\cdot$ Uniaxial creep $\cdot$ Cross-weld $\cdot 316 \mathrm{H} \cdot$ Pre-compressed $\cdot$ Creep ductility

Nomenclature
$A_{A}$
$A_{0}$
$A_{f}$
$B_{r}$
$d_{0}$
$d_{f}$
$l_{0}$
$n$
$n_{A}$
$t_{r}$
$t_{P r i}, t_{S e c}, t_{T e r}$

Norton power-law constant

Stress coefficient in average creep strain law

Initial cross sectional area

Cross sectional area at failure

Coefficient of stress in creep rupture law

Initial diameter

Diameter at failure

Initial gauge length

Creep stress exponent

Average creep stress exponent

Time to rupture

Relative percentage of time accumulation in primary, secondary and tertiary creep stage

A. Mehmanparast

a.mehmanparast@cranfield.ac.uk

1 Department of Mechanical Engineering, Imperial College London, South Kensington Campus, London SW7 2AZ, UK

2 Offshore Renewable Energy Engineering Centre, Cranfield University, Cranfield, Bedfordshire MK43 OAL, UK
$\Delta_{f}$

$\Delta_{\text {load }}$

$\varepsilon_{A c}^{c}$

$\varepsilon_{S}$

$\varepsilon_{f}$

$\varepsilon_{f}^{e n g}, \varepsilon_{f}^{\text {true }}$

$\varepsilon_{p}^{\text {eng }}$

$\varepsilon_{\text {p.load }}$

$\varepsilon_{\text {load }}$

$\varepsilon_{\text {Pri }}^{c}, \varepsilon_{S e c}^{c}, \varepsilon_{T e r}^{c}$

$\sigma_{\text {nom }}$

$\sigma_{\text {true }}$

AR

$\mathrm{BM}$

HAZ

ROA

WM

XW
Axial creep displacement

Axial displacement due to the instantaneous elastic-plastic material response

Average creep strain rate

Secondary (or steady state or minimum) creep strain rate

Uniaxial creep strain at failure (creep ductility)

Engineering, true creep strain at failure (creep ductility)

Engineering axial plastic strain at loading

Engineering strain during load up

Relative percentage of strain accumulated in primary, secondary and tertiary creep stage

Nominal (engineering) stress

True stress

As-Received

Base Metal

Heat Affected Zone

Reduction of Area

Weld Metal

Cross-Weld 


\section{Introduction}

Type $316 \mathrm{H}$ austenitic stainless steel (SS) is widely used in the UK's advanced gas cooled reactor (AGR) power stations. The $316 \mathrm{H}$ SS steam headers used in AGR power plants operate at high temperatures with creep deformation and damage identified as the dominant failure mechanism in these components [1]. As a consequence of operation at elevated temperatures, cracks have been repeatedly found in the heat affected zone (HAZ) of the thick-walled steam header welded components [2-4]. This has been attributed to the creep deformation and crack growth driven by highly triaxial residual stresses $[5,6]$. Therefore, an important issue to be investigated in the life assessment of these steam headers is the characterisation of creep damage and crack growth behaviour of the material particularly in the welded regions. In order to account for the aging effects on the creep properties of the material, it is essential to quantitatively evaluate the creep deformation and rupture behaviour of the welded joints after exposure to service conditions at elevated temperatures. This approach will result in realistic and accurate life predictions using the creep properties which describe the deformation and failure behaviour of aged steam headers.

In order to fill in the knowledge gap, the present study aims to facilitate the evaluation of the remaining life in $316 \mathrm{H}$ welded steam header components by performing uniaxial creep rupture tests on cross-weld specimens. For this purpose, uniaxial round bar samples with the HAZ (here referred to as cross-weld, XW) region located at the mid-length of the gauge region have been tested in this work to quantify the uniaxial creep properties of the HAZ material in ex-service header components. Knowing that significant levels of pre-straining is introduced into the steam header components during the manufacturing processes such as bending, rolling and welding, the results from the present study are compared with those of available on the as-received (AR) material and also pre-strained material under compression (PC) to examine the influence of material pre-straining on the mechanical response and creep deformation and failure behaviour of the material.

Whilst the creep properties of the AR $316 \mathrm{H} \mathrm{[7-9]} \mathrm{and}$ welded joints $[10,11]$ have been extensively investigated by various researchers, the tests performed in previous works were relatively short-term and did not replicate the long-term behaviour of the high temperature components. In addition, creep testing on XW specimens is costly and due to the limitation in material availability, performing a large number of tests on XW specimens is impractical. Therefore, there is a need to develop an experimental technique to replicate the XW material conditions in a simpler fashion using which more tests can be performed to understand the long-term behaviour of the XW material. Moreover, the influence of material pre-straining on creep deformation and life assessment of high temperature components has only received some attention in recent years [12-14] and these effects were not extensively studied before.

It has been shown in previous studies [15-18] that plastic pre-straining significantly reduces the creep ductility of the material, compared to the as-received material state. Further shown in the literature is that the creep crack growth $(\mathrm{CCG})$ behaviour of the pre-compressed $316 \mathrm{H}$ stainless steel material is similar to the HAZ specimens which is hypothesised to be due to similar creep deofmration and ductility in the PC and HAZ material states [15]. To invesitigate the hypothesis suggested in [15] about the similarity of uniaxial creep properties in the PC and HAZ materials and relate these properties to the CCG behaviour in high temperature compinents, the uniaxial creep results from ex-service cross-weld HAZ specimens presented in the current study are compared with those of avaibale on the AR and PC materials. The findings from this study have been discussed in terms of the replication of the pre-strains induced during welding process by performing tests are pre-strained materials with similar creep properties. This proposed approach helps to characterise the creep deformation and crack growth behaviour in high temperature welded components without needing to perform tests on specimens extracted from weldments, which is a relatively expensive and time consuming process.

\section{Creep Deformation and Rupture Rules}

Uniaxial creep rupture tests are performed to determine the creep deformation and strain at failure of the material under different load levels at elevated temperatures. By performing a uniaxial creep test and plotting the creep curve, the proportion of the creep strain accumulated and the time spent in each stage of the creep curve (i.e. primary, secondary and tertiary creep regions) and also the uniaxial creep properties of the material can be identified.

As shown and discussed in [19], for a power-law creeping material the secondary (i.e. steady state) creep strain rate, $\dot{\varepsilon}_{s}$, and average creep strain rate, $\varepsilon_{A}^{c}$, can be described as;

$$
\begin{aligned}
& \dot{\varepsilon}_{s=} A \sigma^{n} \\
& \varepsilon_{A}^{c}=A_{A} \sigma^{n_{A}}
\end{aligned}
$$

where $\sigma$ is the applied stress, $n$ and $n_{A}$ are the steady state and average power-law creep stress exponent, respectively, and $A$ and $A_{A}$ are temperature dependent material constants corresponding to secondary and average creep strain rate, respectively. Similarly, the creep rupture time, $t_{r}$, of the material may be defined using a power-law relationship as [19];

$t_{r}=B_{r} \sigma^{-v_{r}}$ 
where $B_{r}$ is the temperature dependent rupture time constant and $v_{r}$ is the rupture life stress exponent.

The uniaxial creep strain at failure, $\varepsilon_{f}$, (also known as creep ductility) can be defined and reported as axial elongation and reduction of area (ROA). The engineering definition of axial creep ductility and ROA can be expressed as [16];

$\left.\varepsilon_{f}^{\text {eng }}\right|_{\text {axial }}=\frac{\Delta_{f}-\Delta_{\text {load }}}{l_{0}}=\frac{\Delta_{c}}{l_{0}}$

$\left.\varepsilon_{f}^{\text {eng }}\right|_{R O A}=\frac{A_{0}-A_{f}}{A_{0}}-\varepsilon_{p, \text { load }}^{\text {eng }}=2 \ln \left(\frac{d_{0}}{d_{f}}\right)-\varepsilon_{p, \text { load }}^{\text {eng }}$

where $\Delta_{f}$ is the total displacement, $\Delta_{\text {load }}$ is the axial displacement measured during load up, $\Delta_{c}$ is the creep displacement, $l_{0}$ is the initial gauge length, $A_{0}$ is the initial cross sectional area, $A_{f}$ is the final cross sectional area at failure, $d_{0}$ is the initial diameter, $d_{f}$ is the final diameter at failure region and $\varepsilon_{p \text {,load }}^{\text {eng }}$ is axial plastic strain at the end of loading. Note that in those uniaxial creep tests where diametric strain measurements are not available, equation (5) can be used to provide an estimate of the ROA value by subtracting the total ROA from the axial plastic strain measured during the load up process.

The true definition of failure strain, $\varepsilon_{f}^{\text {true }}$, and net section stress, $\sigma_{\text {true }}$, can be written as [20];

$\varepsilon^{\text {true }}=\ln \left(1+\varepsilon^{\text {eng }}\right)$

$\sigma^{\text {true }}=\sigma_{\text {nom }}\left(1+\varepsilon^{\text {eng }}\right)$

where $\sigma_{\text {nom }}$ is the engineering (i.e. nominal) stress and $\varepsilon^{\text {eng }}$ is the engineering strain. Note that all the results obtained from uniaxial creep rupture tests are presented in this paper based on the true stress and strain definition.

\section{Tensile Test Results}

In order to characterise the mechanical behaviour of the material examined in this study, tensile tests were initially performed on XW specimens at room temperature and $550{ }^{\circ} \mathrm{C}$. Tensile tests were performed on Type $316 \mathrm{H}$ SS ex-service specimens consisting of the BM, WM and HAZ. Digital image correlation (DIC) technique was used to capture the strain maps across three material microstructures in the room temperature and high temperature tensile tests. Three tensile tests were performed at each temperature and the results are presented and discussed in this section.

Prior to the DIC tensile test, one side of the specimens was ground and etched to reveal the microstructure of the weld. The weld areas were marked in order to observe the failure positions. The specimens were initially lightly coated with matt black paint and subsequently white speckles were applied using an airbrush to produce a high contrast speckle pattern on the test specimens. The average speckle diameter created for DIC testing was approximately $0.03 \mathrm{~mm}$. Once the speckle pattern was applied, the test specimens were loaded into a tensile testing machine with a $30 \mathrm{kN}$ load cell. For the purpose of DIC measurement, a stereo camera system consisting of two 5 megapixel monochrome cameras with $100 \mathrm{~mm}$ lenses was used. This set-up was capable of capturing the out-of-plane displacements such as necking.

An initial image on the undeformed sample was taken to capture the initial location of the speckle reference points and subsequent images were acquired every $5 \mathrm{~s}$ throughout the tests. Each deformed image was correlated with the initial undeformed image to convert the displacement data into the full-field displacement gradient tensor. The images were postprocessed using GOM software Aramis v6.3.0 [21]. A facet size of 19 pixels with 4 pixel overlap was chosen to capture the strain field on the test specimens. A single pass of a smoothing algorithm was applied to reduce the noise by averaging the strains over a $3 \times 3$ grid of facets.

\section{Room Temperature Tensile Behaviour}

Three dog-bone shape specimens, denoted RT-T-1, RT-T-2 and RT-T-3, with the cross sectional area of $25 \mathrm{~mm}^{2}$ were tested at room temperature with a constant displacement rate of $1 \mathrm{~mm} / \mathrm{min}$. During the tensile tests, the strain distributions in the loading direction were continuously measured using DIC technique. As seen in Fig. 1, the strain distribution maps were recorded during the entire loading procedure until failure occurred. As observed in the strain distribution map in Fig. 1, the fracture generally occurred in the weld region, close to $\mathrm{WM}$ and BM boundary. Figure 2 shows the strain variation map at $25 \%, 50 \%, 75 \%$ and $100 \%$ of the test duration, along a selected straight line including 68 strain sampling points. It can be seen in this figure that the strain evolution in the HAZ

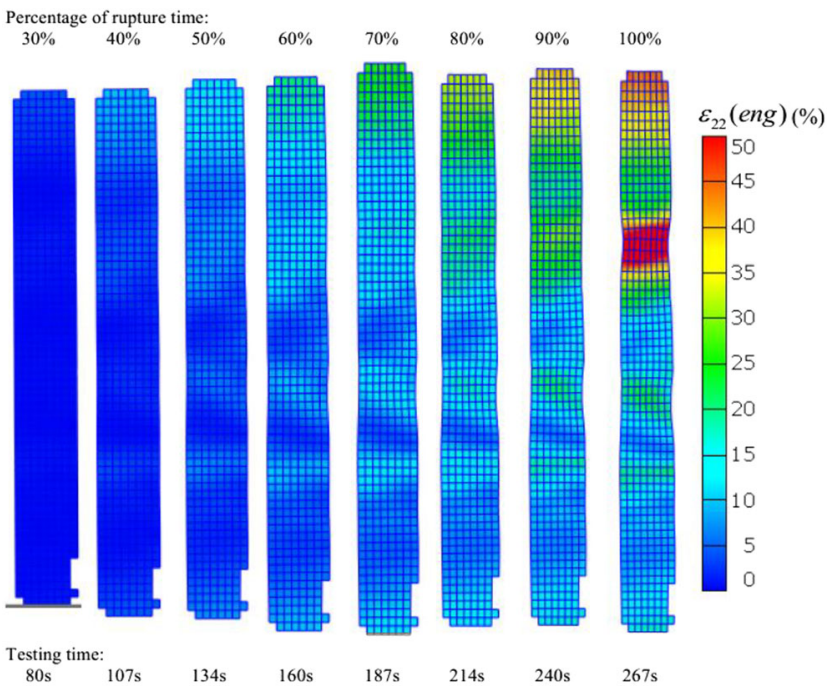

Fig. 1 The DIC strain distribution map along the loading direction at stages of the test 
Fig. 2 DIC strain distribution map at different stages of the test, along a straight line
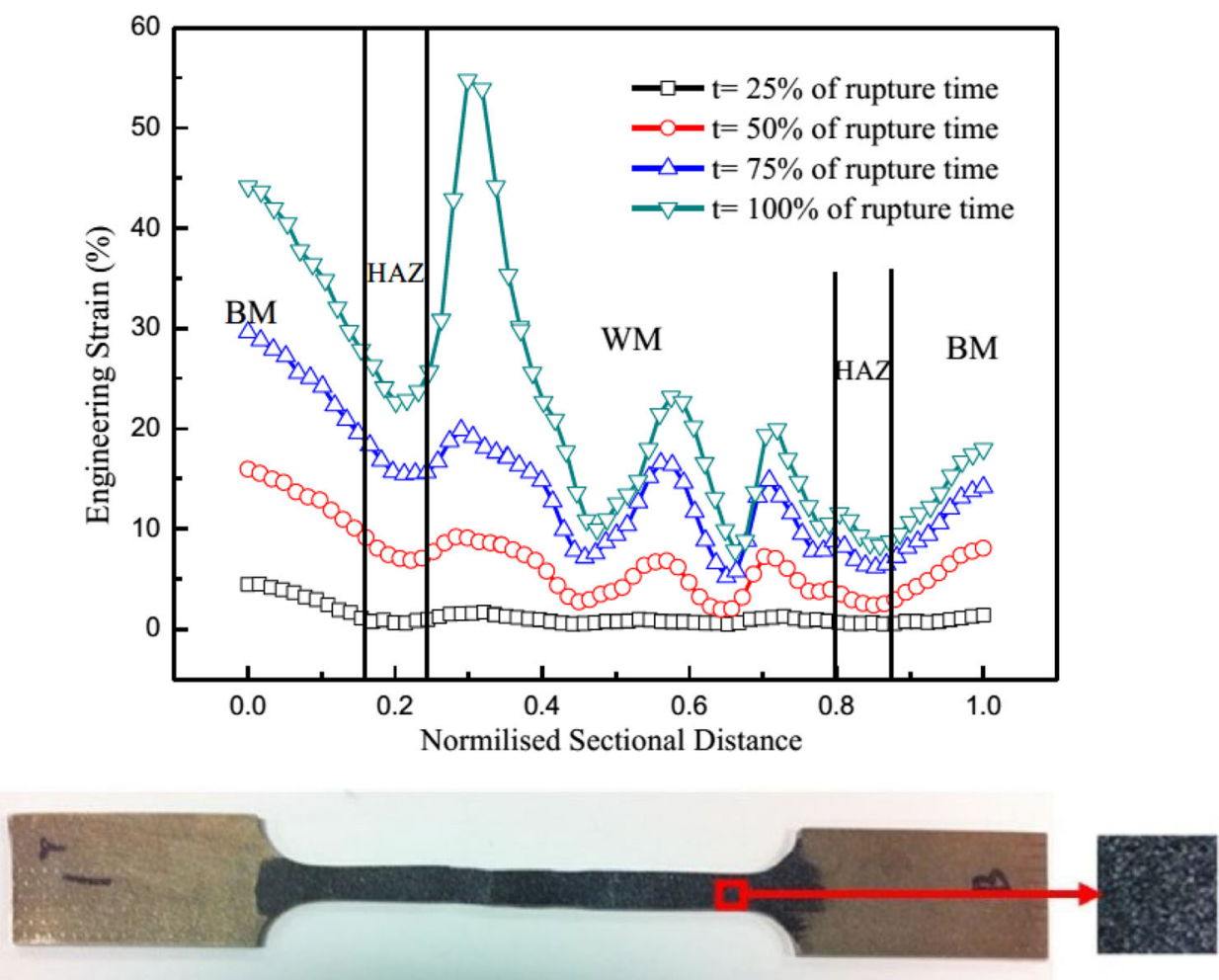

region was noticeably lower than the strains in the neighbouring WM and BM regions at different stages of the test. A strain fluctuation within the WM can be observed, which could result from individual multi-weld passes in the examined XW specimens.

The engineering stress vs. engineering strain curves obtained from the room temperature tensile tests on XW specimens are presented in Fig. 3. It must be noted that the presented results in Fig. 3 include the average values of strain obtained from three test specimens at a given value of applied stress, therefore only one set of data is presented in this figure. Three

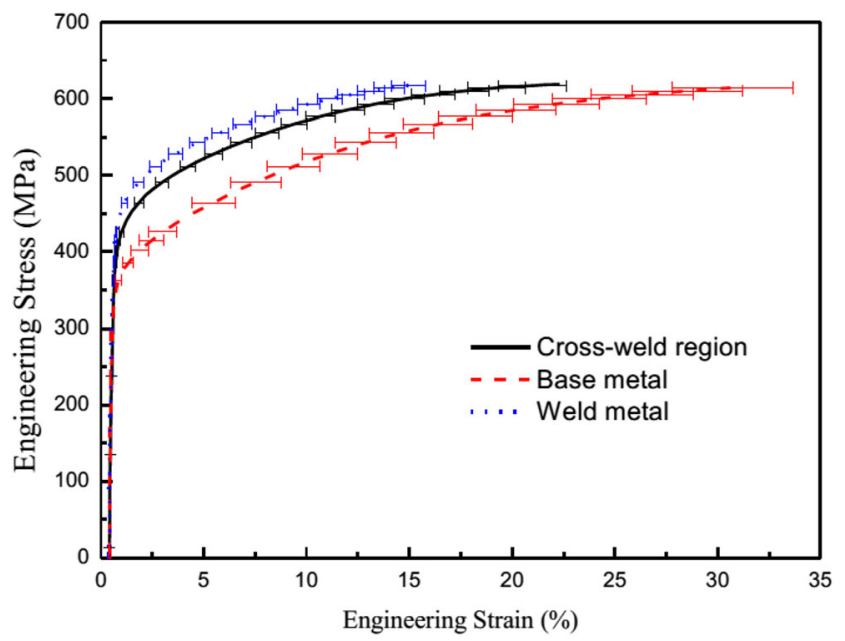

Fig. 3 Room temperature tensile curves for the BM, WM and XW materials distinct tensile curves have been plotted in Fig. 3 to demonstrate the room temperature tensile behaviour of the material in the XW, BM and WM regions. The elastic Young's modulus, $E$, and $0.2 \%$ proof stress, $\sigma_{0.2}$, obtained from each data set are summarised in Table 1. As seen in Fig. 3 and Table 1, the same room temperature elastic Young's modulus of $E=$ $205 \mathrm{GPa}$ was obtained for the BM, WM and XW region whereas the $\sigma_{0.2}$, which is often taken as the yield stress of the material, showed a variation in different regions. It can be seen in Table 1 that the $0.2 \%$ proof stress in the $\mathrm{XW}$ region is around $50 \mathrm{MPa}$ higher and $20 \mathrm{MPa}$ lower than BM and WM regions, respectively. The comparison shown in Table 1 and Fig. 3 clearly indicate that the $0.2 \%$ proof stress of the XW material is higher than the BM (also known as AR material) implying material pre-straining hence hardening effects introduced into the material during the welding process [22].

Table 1 Room temperature and high temperature tensile properties

\begin{tabular}{llll}
\hline Material & Temperature & $E(\mathrm{GPa})$ & $\sigma_{0.2}(\mathrm{MPa})$ \\
\hline XW & Room & 205 & 385 \\
BM & Room & 205 & 331 \\
WM & Room & 205 & 404 \\
XW & High & 155 & 275 \\
BM & High & 140 & 185 \\
WM & High & 150 & 257 \\
\hline
\end{tabular}




\section{High Temperature Tensile Behaviour}

The high temperature tensile behaviour of the XW material at $550{ }^{\circ} \mathrm{C}$ is plotted in Fig. 4. Similar to the room temperature test results, for a given value of applied stress the average DIC strain values captured from all three specimens has been calculated and presented in Fig. 4. It was observed that similar to the room temperature tensile samples, the high temperature tensile specimens fractured near the WM, close to the fusion line. The elastic Young's modulus and $0.2 \%$ proof stress values obtained from the $\mathrm{XW}, \mathrm{BM}$ and $\mathrm{WM}$ tensile curves were quantified and presented in Table 1 . It can be seen in Fig. 4 and Table 1 that the $0.2 \%$ proof stress of the BM is considerably smaller than the WM and XW regions. The results in Table 1 show that the $0.2 \%$ proof stress of XW is $90 \mathrm{MPa}$ and $18 \mathrm{MPa}$ higher than BM and WM, respectively. Also seen in Table 1 is that the similar values of Young's modules have been obtained from three regions within the test specimens. The comparison of the tensile curves in Fig. 4 shows that similar to the material's behaviour at room temperature, the XW specimen exhibits significant hardening behaviour, compared to the $\mathrm{BM}$, confirming that the pre-strains have been accumulated in the XW specimen during the welding process.

\section{Uniaxial Creep Test Results}

\section{Specimen Preparation}

The ex-service material used in this study was a $316 \mathrm{H}$ SS steam header (i.e. denoted Header A in the present study) taken from one of the UK's AGR power stations supplied by EDF Energy. The component was in service for $87,790 \mathrm{~h}$ at operating temperature of around $550{ }^{\circ} \mathrm{C}$, hence it was significantly aged under the

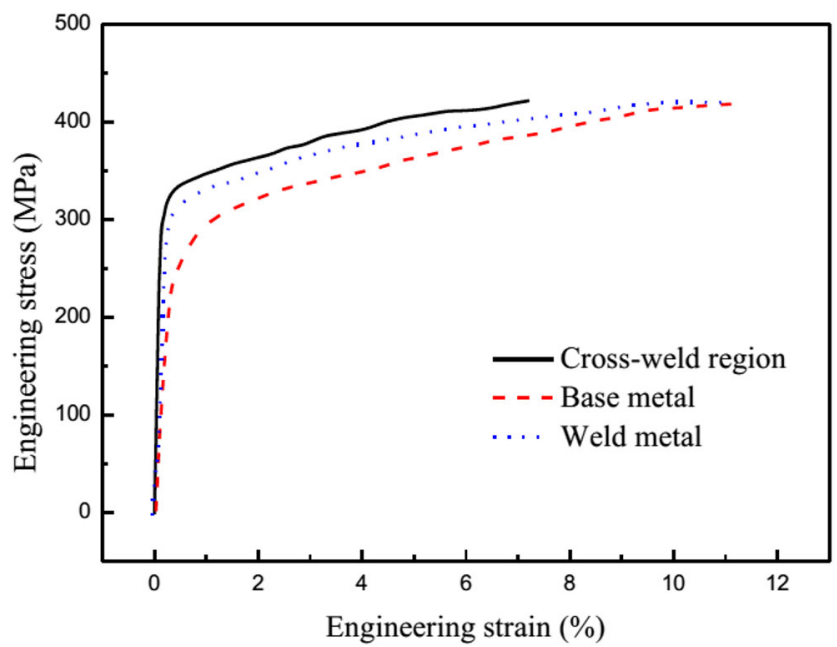

Fig. 4 Tensile response from DIC measurement in different regions at high temperature based on engineering stress and strain operational loading conditions. Uniaxial creep specimens were extracted from the ex-service header from the welded region where a nozzle was attached to the thick-walled steam header using manual metal arc welding. Four uniaxial specimens, denoted UC-1 -4 , were extracted with the initial gauge length of $l_{0}=36 \mathrm{~mm}$, average diameter $d=8 \mathrm{~mm}$ and M12 threads at the gripping ends. The samples were machined with ridges at the beginning and end of the gauge region to accommodate extension legs for strain measurements outside the furnace using a linear variable differential transformer (LVDT). These specimens were designed in such a way that the BM, WM and HAZ material microstructures were located at the mid-length of the gauge region. The macroscopic picture of the uniaxial specimens and the schematic location of the BM, WM and HAZ region within the gauge region are illustrated in Fig. 5. As seen in this figure, the sections from which the XW specimens were extracted had to be polished and etched first to reveal the material microstructure and ensure that the extracted uniaxial specimens contain the BM, $\mathrm{WM}$ and $\mathrm{HAZ}$ region.

\section{Creep Deformation and Rupture Results}

The uniaxial creep rupture tests were carried out at $550{ }^{\circ} \mathrm{C}$ and analysed following ASTM E 139-11 standard [23]. The specimens were tested under nominal stress levels ranging between 290 and $345 \mathrm{MPa}$ and the results are summarised in Tables 2 and 3. The fracture position in all specimens was found to be near the boundary between the BM and WM, near the fusion line. The accumulated strain during the load up process, $\varepsilon_{\text {load }}$, the plastic component of strain during the load up process, $\varepsilon_{p}$, load, the creep ductility based on the axial displacement, $\varepsilon_{f}$ Axial, and the creep ductility calculated based on ROA, $\varepsilon_{f}$ ROA, from all four testes are shown in Table 2. Further creep test results which include the creep rupture time, $t_{r}$, the steady state creep strain rate, $\varepsilon_{s}^{c}$, and the average creep strain rate, $\varepsilon_{A}^{c}$, from each test are shown in Table 3 . Also included in Table 3 are the proportion of time and creep strain in each of the three parts of the creep curves.

It can be seen in Table 2 that the plastic strain accumulated in the specimens during the load up process is proportional to the applied stress level with the values ranging from $0.34 \%$ and $3.37 \%$ for the range of stresses examined in this study. The creep curves obtained from these four tests, which were performed at relatively high stress levels, are plotted and compared with each other in Fig. 6. As seen in this figure, a continuous reduction in the rupture time is observed by increasing the applied stress in all creep tests performed on XW specimens in this study. Also seen in Fig. 6 is that no particular trend can be inferred for the obtained creep ductility data points. This observation is consistent with the previous studies by Mehmanparast [17], Spindler [24] and Bettinson [25]. According to Table 2, the average values of creep ductility calculated based on axial displacement and ROA is $5.8 \%$ and $18.3 \%$, respectively. It is worth noting that the higher 
Fig. 5 The location of weldments in four uniaxial creep rupture specimens examined

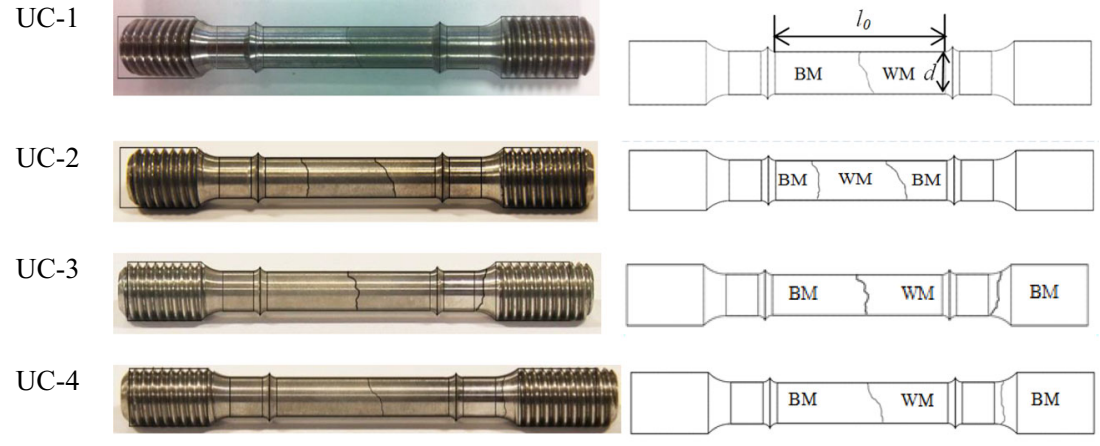

value of creep ductility based on ROA measurements is due to the fact that in this method the strains are measured local to the failure region using the change in the dimeter of the specimen, therefore they are expected to result in greater values compared to the axial displacement method.

The relative proportions of the time spent and creep strain accumulated in the primary, secondary and tertiary creep regions are tabulated in Table 3 and illustrated in Figs. 7 and 8, respectively. As clearly seen in Fig. 7, the proportion of time elapsed in primary and tertiary creep regions progressively reduce by increasing the applied stress level whereas the time spent in the secondary creep region increases. The largest proportion of the creep test duration in these four specimens has been found in the secondary creep region, particularly in the tests performed at higher stress tests. The percentage of creep strain accumulation in each creep region, exhibited in Fig. 8, shows that by increasing the applied stress level the amount of strain accumulated in primary and tertiary creep regions generally reduce while the percentage of strain accumulated in the secondary region increases. Comparing the results shown in Figs. 7 and 8 it can be deduced that similar variations are observed in the percentage of time elapsed and creep strain accumulated in each creep region, by changing the applied stress level.

\section{Power-Law Creep Properties}

The secondary creep strain rate, $\varepsilon_{s}^{c}$, average creep strain rate, $\varepsilon_{A}^{c}$, and rupture time, $t_{r}$, obtained from all four specimens have been given in Table 3 and plotted in Figs. 9, 10 and 11, respectively. As seen in these three figures, the slope and intercept of the resulting regression lines have been determined to identify uniaxial creep power-law constants (see equations (1), (2) and (3)) for XW specimens. As seen in Figs. 9, 10 and 11 two lines of best fit have been made to the data points; the red dashed line is the regression fit to the data points and the black solid line is the best fit to the data points using the least squared method by assuming a fixed slope taken from the line of best fit to the $8 \%$ precompressed and as-received specimens reported in [17, 18]. Note that more data points were available for the AR and PC specimens in $[17,18]$ compared to the XW specimens examined in this study, therefore the fixed slope fits were made to account for possible uncertainties caused by the limited number of data points available from the cross-weld specimens. It is also worth noting that the AR and PC specimens tested in $[17,18]$ were taken from the same steam header that the XW specimens were extracted from (Header A), hence they had the same aging history and the results are directly comparable with each other. The steady state creep strain rate, average creep strain rate and rupture time power-law constants from both fits to the XW data points are summarised in Table 4. Also included in this table are the power-law constants from the AR and PC specimens taken from [17, 18].

As seen in Table 4, Figs. 9, 10 and 11 by fixing the slope of the line of best fit, the power-law coefficients obtained from $\mathrm{XW}$ data points are found similar to those of reported for AR and PC materials for the steady state creep strain rate, average creep strain rate and the rupture time. This indicates that the power-law creep properties of the ex-service XW specimens examined in this study can be taken from the AR and PC data sets obtained from the same aged component. This is a very important observation given that the extraction of the XW

Table 2 A summary of uniaxial creep specimen dimensions and test results

\begin{tabular}{lllllllllllll}
\hline Test ID & $d(\mathrm{~mm})$ & $l_{0}(\mathrm{~mm})$ & $\sigma_{\text {nom }}(\mathrm{MPa})$ & $\sigma_{\text {true }}(\mathrm{MPa})$ & $\varepsilon_{\text {load }}^{\text {eng }} \%$ & $\varepsilon_{\text {load }}^{\text {true }} \%$ & $\varepsilon_{p, \text { load }}^{\text {eng }} \%$ & $\varepsilon_{f}^{\text {eng }}$ Axial $\%$ & $\varepsilon_{f}^{\text {true }}$ & Axial $\%$ & $\varepsilon_{f}^{\text {eng }} \mathrm{ROA} \%$ & $\varepsilon_{f}^{\text {true }} \mathrm{ROA} \%$ \\
\hline $\mathrm{UC}-1$ & 8.05 & 35.45 & 290 & 293 & 1.12 & 1.11 & 0.34 & 4.62 & 4.52 & 17.42 & 19.22 \\
$\mathrm{UC}-2$ & 8.07 & 35.90 & 325 & 338 & 4.06 & 3.98 & 2.83 & 8.18 & 7.94 & 13.08 \\
$\mathrm{UC}-3$ & 8.06 & 35.95 & 345 & 361 & 4.54 & 4.44 & 3.37 & 5.42 & 5.28 & 23.34 & 27.76 \\
$\mathrm{UC}-4$ & 7.01 & 35.91 & 300 & 306 & 2.27 & 2.24 & 1.26 & 5.50 & 5.39 & 10.84 \\
\hline
\end{tabular}


Table 3 Uniaxial creep test results

\begin{tabular}{lllllllll}
\hline Test ID & $t_{r}(\mathrm{~h})$ & $\varepsilon_{s}^{c}\left(\mathrm{~h}^{-1}\right)$ & $\varepsilon_{A}^{c}\left(\mathrm{~h}^{-1}\right)$ & $\varepsilon_{P r i}^{c} \%$ & $\varepsilon_{S e c}^{c} \%$ & $\varepsilon_{\text {Ter }}^{c} \%$ & $t_{P r i} \%$ & $t_{S e c} \%$ \\
\hline UC-1 & 1147 & $0.23 \times 10^{-4}$ & $0.40 \times 10^{-4}$ & 17.2 & 26.5 & 56.3 & 25.2 & 39.2 \\
UC-2 & 369 & $1.20 \times 10^{-4}$ & $2.21 \times 10^{-4}$ & 22.3 & 34.7 & 43.0 & 21.8 & 49.0 \\
UC-3 & 138 & $3.54 \times 10^{-4}$ & $3.93 \times 10^{-4}$ & 11.2 & 46.3 & 42.5 & 20.3 & 61.3 \\
UC-4 & 585 & $0.67 \times 10^{-4}$ & $0.94 \times 10^{-4}$ & 7.1 & 69.4 & 23.5 & 11.1 & 76.3 \\
\hline
\end{tabular}

specimens is quite time-consuming as the material needs to be polished and etched first before machining the samples to ensure that the BM, WM and HAZ regions are located within the gauge length of the uniaxial creep specimen. Therefore, based on the observations from the present study the uniaxial creep properties of the XW material can be taken from the AR and PC material without the need to perform tests on the XW specimens.

\section{Comparison between Creep Properties of Cross-Weld, Pre-Compressed and as-Received Specimens}

It has been shown in the previous study by Mehmanparast et al. [15] that the CCG behaviour of $8 \%$ pre-compressed $316 \mathrm{H}$ stainless steel material is similar to the XW specimens. As discussed in [15] this is thought to be due to similar values of creep ductility and also creep strain rate power-law constants in the PC and XW material. In order to confrim this thought, the uniaxial creep results from XW specimens are compared with those of avaibale on the AR and PC materials in this section. It must be noted that the steam header component from which the XW specimens were extracted in this study is denoted Header A from which AR and PC test data are also available. Moreover, for a wider comparison between various aged components, the reults from AR and PC test

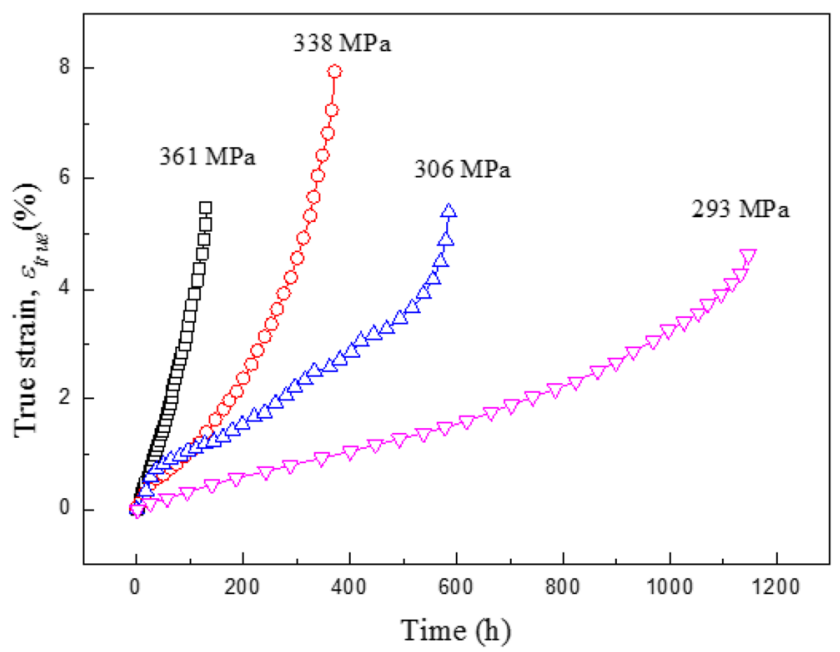

Fig. 6 Creep curves obtained from cross-weld specimens specimens extracted from another two steam headers with the same cast, denoted Header B and Header C, have also been included in the figures presented in this section.

\section{Creep Ductility}

The variation in axial and ROA creep ductility against true stress in XW specimens extracted from Header A is compared with the PC and AR data available from the same header in Figs. 12 and 13. As seen in Figs. 12 and 13 the creep ductility of the XW specimens, particularly when the data are presented in terms of ROA, has been found sensitive to the stress level and exhibits some degree of stress dependency, similar to that of observed in the PC material. However, the data points available on the AR material are quite scattered and no particular trend can be inferred for the AR material state. As discussed in Ref [26], the obtained results from the tests performed on the AR material at relatively high stress levels exhibit a stress independent trend within the experimental scatter, with large values of standard deviation. Therefore, as seen in Figs. 12 and 13 the level of scatter in the AR material doesn't allow a direct comparison being made with the $\mathrm{PC}$ and XW material states. Therefore, an alternative approach needs to be employed to derive a meaningful correlation between the

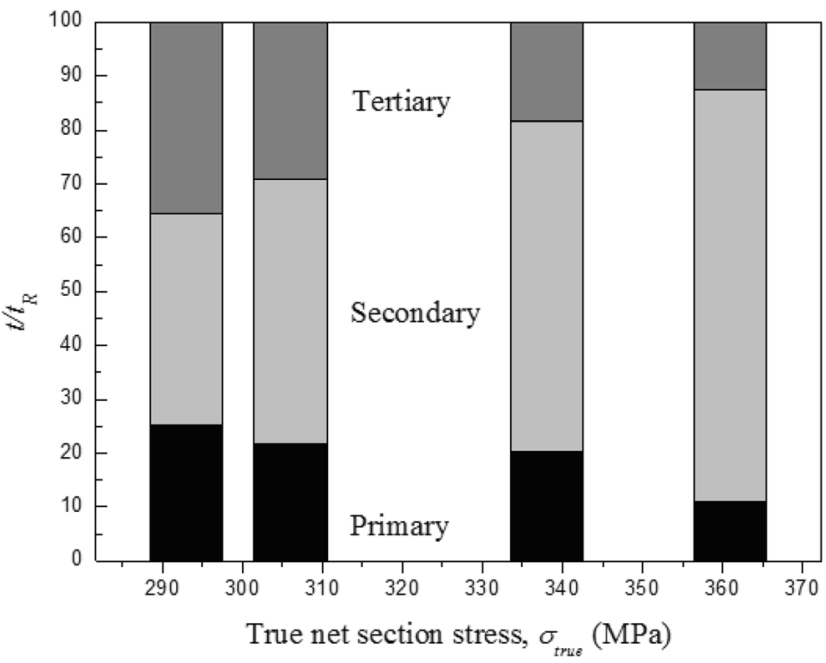

Fig. 7 Relative percentage of time spent in each creep region for crossweld specimens 


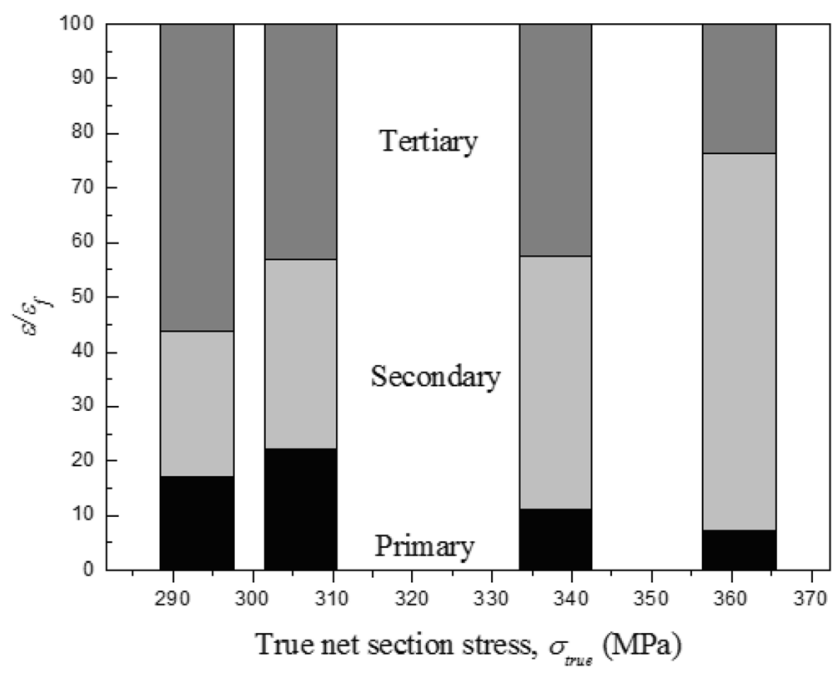

Fig. 8 Relative percentage of strain accumulated in each creep region for cross-weld specimens

creep ductility of the materials with and without preconditioning.

In order to further examine the stress dependency of creep ductility in XW specimens, the creep ductility trend estimated for $316 \mathrm{H}$ at $550{ }^{\circ} \mathrm{C}$ by Mehmanparast et al in Refs [26-28] have been used in this study which consist of three regions; an upper shelf stress independent region at large values of applied stress, a lower shelf stress independent region at low values of stress and a stress dependent transition region in between. As explained in Ref [26] clear creep ductility trends can be observed when the data are correlated with the applied stress level normalised by $0.2 \%$ proof stress of the material at the given temperature. According to the creep ductility model proposed in $\operatorname{Ref}$ [26] the lower shelf axial creep ductility value for $316 \mathrm{H} \mathrm{SS}$ at $550{ }^{\circ} \mathrm{C}$ is approximately $0.9 \%$ for $\sigma / \sigma_{0.2}<1.06$ whereas the upper shelf value is around $13.6 \%$ for $\sigma / \sigma_{0.2}>$ 1.32. It has been shown and discussed in Ref [26] that the stress independent creep ductility trends at the upper shelf

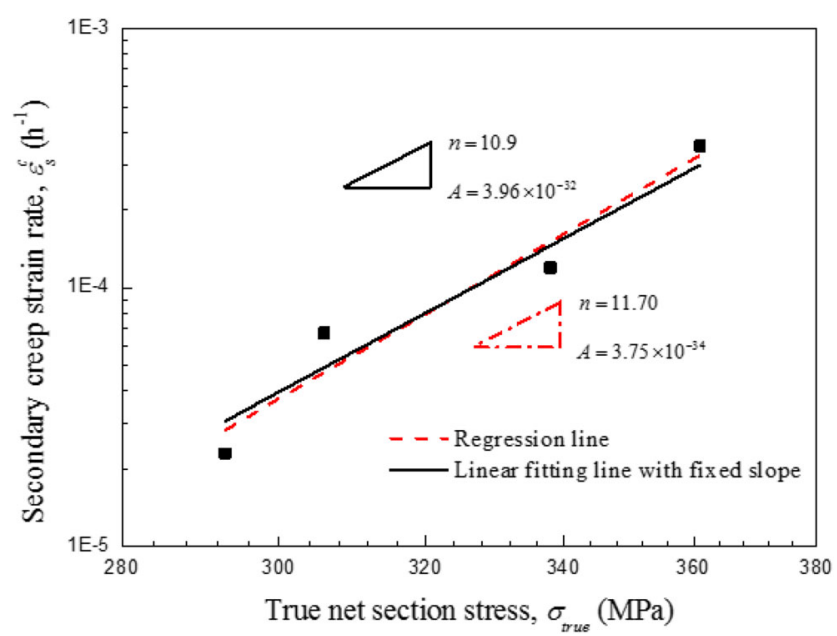

Fig. 9 Determination of minimum creep strain rate power-law constants for cross-weld specimens

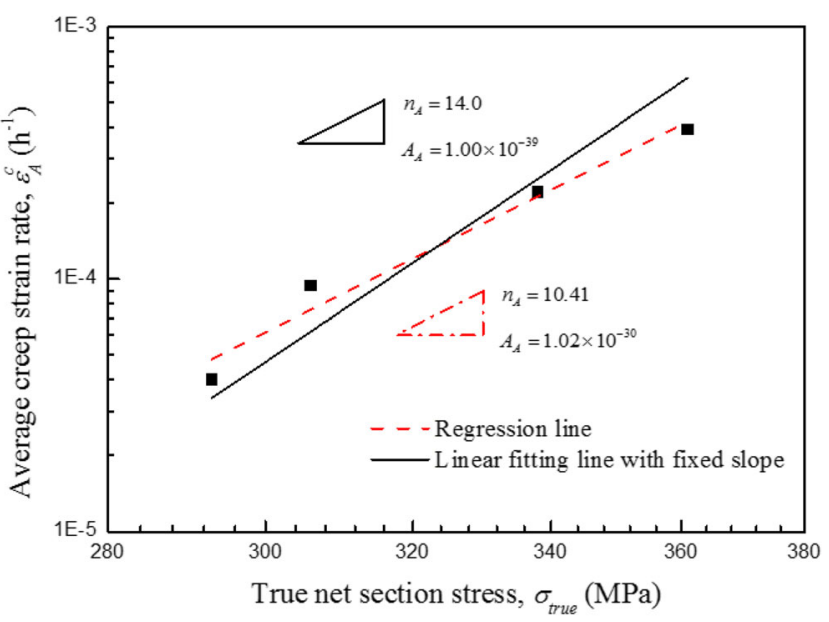

Fig. 10 Determination of average creep strain rate power-law constants for cross-weld specimens

and lower shelf regions are due to the same values of the average creep strain rate and rupture time power-law stress exponents.

The stress dependency of the XW specimens' data has been examined by plotting the creep ductility data obtained from all specimens tested in this work against the stress normalised by the $0.2 \%$ proof stress of the material at $550{ }^{\circ} \mathrm{C}$ in Fig. 14. These data are compared with those of available from the AR and $8 \%$ PC material at the same temperature and also the proposed creep ductility trends in Ref [26] for the AR material in the regions where there was no experimental data available in the open literature. Note that $0.2 \%$ proof stress values of the examined AR, $8 \% \mathrm{PC}$ and $\mathrm{XW} 316 \mathrm{H}$ materials at $550{ }^{\circ} \mathrm{C}$ are around $170 \mathrm{MPa}$ [26], $260 \mathrm{MPa}$ [17] and $275 \mathrm{MPa}$, respectively. For the XW specimens tested in the present study, the applied stress range was $1.06<\sigma / \sigma_{0.2}<1.32$ where $\sigma_{0.2}$ for the XW $316 \mathrm{H}$ material at $550{ }^{\circ} \mathrm{C}$ is $275 \mathrm{MPa}$.

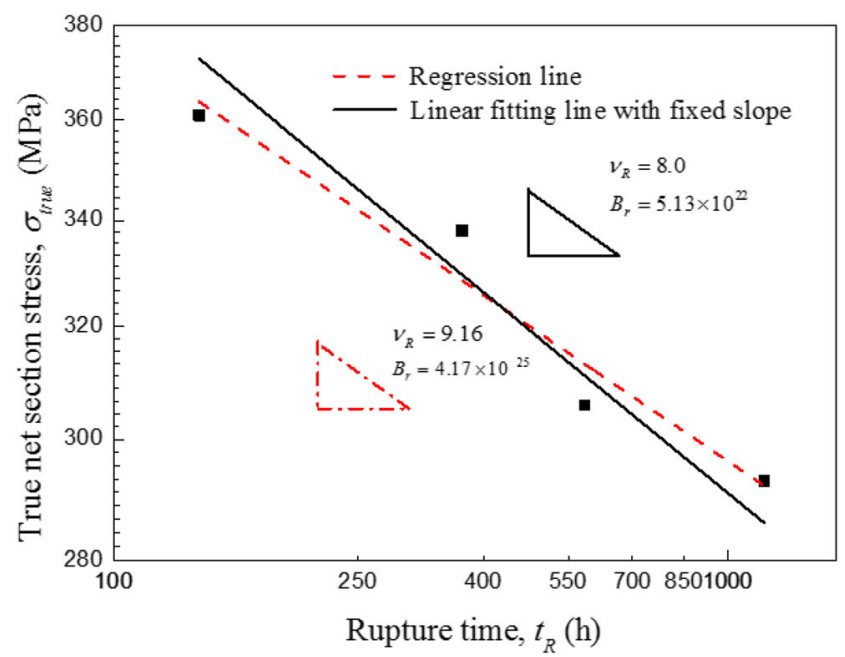

Fig. 11 Determination of rupture time power-law constants for crossweld specimens 
Table 4 Summary of power-law constants for $\mathrm{XW}, \mathrm{AR}$ and $\mathrm{PC}$ specimens

\begin{tabular}{llllllll}
\hline $\begin{array}{l}\text { Material } \\
\text { condition }\end{array}$ & $\begin{array}{l}\text { Best fit } \\
\text { method }\end{array}$ & $\begin{array}{l}A \\
\left(\mathrm{MPa}^{-\mathrm{n}} \mathrm{h}^{-1}\right)\end{array}$ & $n$ & $\begin{array}{l}A_{A} \\
\left(\mathrm{MPa}^{-\mathrm{n}} \mathrm{h}^{-1}\right)\end{array}$ & $n_{A}$ & $\begin{array}{l}B_{r} \\
\left(\mathrm{MPa}^{v} \mathrm{~h}\right)\end{array}$ & $\nu_{r}$ \\
\hline $\mathrm{XW}$ & Regression fit & $3.75 \times 10^{-34}$ & 11.70 & $1.02 \times 10^{-30}$ & 10.41 & $4.17 \times 10^{25}$ & 9.16 \\
$\mathrm{XW}$ & Fixed slope & $3.96 \times 10^{-32}$ & 10.9 & $1.00 \times 10^{-39}$ & 14.0 & $5.13 \times 10^{22}$ & 8.0 \\
$\mathrm{AR}$ & Regression fit & $2.68 \times 10^{-32}$ & 10.9 & $9.82 \times 10^{-40}$ & 14.0 & $6.61 \times 10^{22}$ & 8.0 \\
$\mathrm{PC}$ & Regression fit & $2.22 \times 10^{-32}$ & 10.9 & $8.97 \times 10^{-39}$ & 14.0 & $5.45 \times 10^{22}$ & 8.0 \\
\hline
\end{tabular}

As seen in Fig. 14, the creep ductility values obtained from the PC and XW specimens agree well with the estimated normalised trend for the AR material, when all the data are plotted against the stress divided by the $0.2 \%$ proof stress of the material. Given that the creep tests on the AR $316 \mathrm{H}$ material at $550{ }^{\circ} \mathrm{C}$ is timeconsuming due to the large ductility of the material, hence a longer time required to reach creep failure, this may suggest that relatively shorter term tests on the PC and XW specimens could provide an acceptable estimate of the lower shelf creep ductility of the AR material in much shorter time scales. Moreover, the results in Fig. 14 suggest that the short-term and long-term integrity assessment of the XW sections of service exposed steam header components can be made using the general trend proposed by Mehmanparast et al [26] for the creep ductility of the material with AR, PC and XW conditions. This is a valuable conclusion given that the extraction and testing of XW specimens is often difficult and time-consuming, therefore the proposed trend shown in Fig. 14 can be used to employ the accurate estimate of creep ductility in CCG prediction analysis of welded components operating at elevated temperatures.

\section{Uniaxial Creep Properties}

The secondary creep strain rate $\varepsilon_{S}^{c}$, average creep strain rate $\varepsilon_{A}^{c}$, and rupture time $t_{R}$ data obtained from XW specimens extracted from Header A are plotted against the true stress in Figs. 15, 16

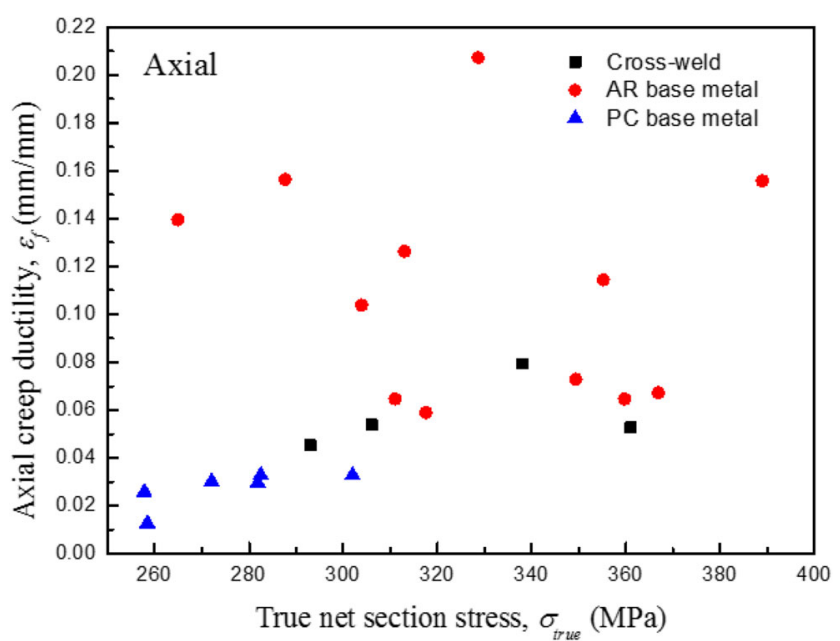

Fig. 12 Axial creep ductility vs. true stress for the XW, AR and PC materials and 17, respectively. Also included in these figures are the AR and PC data obtained from the specimens extracted from different steam headers of the same cast, for comparison purposes. As discussed in Section 4.3, the power-law constants from the lines of best fits to the XW data points were found similar to those of obtained from AR and PC materials. In order to make a direct and clear comparison between different steam headers, the results available in Ref [17] on Header B and Header C have been reanalysed based on the assumption that within the experimental scatter the slope of the materials extracted from different headers are the same as those obtained from the PC specimens in Header A which is the data set with the largest number of data points. The power-law creep constants determined from these fixed slope fits are summarised in Table 4 and shown in Figs. 15, 16 and 17.

It can be seen in Fig. 15 that for a given value of stress the secondary creep strain rate $\bar{\varepsilon}_{s}^{c}$ for XW specimens is slightly higher than the AR material extracted from the same header and the AR material itself exhibits a higher trend than the PC. Also seen in Fig. 15 is that a relatively large variation can be observed in the secondary creep strain rate trends for the AR material in Header A, Header B and C. The average creep strain rate results in Fig. 16 show that similar trends are found for the $\mathrm{XW}, \mathrm{AR}$ and PC materials extracted from different headers except the AR power-law trend from Header B and $\mathrm{C}$ which is marginally lower than other trends. This may imply that at least

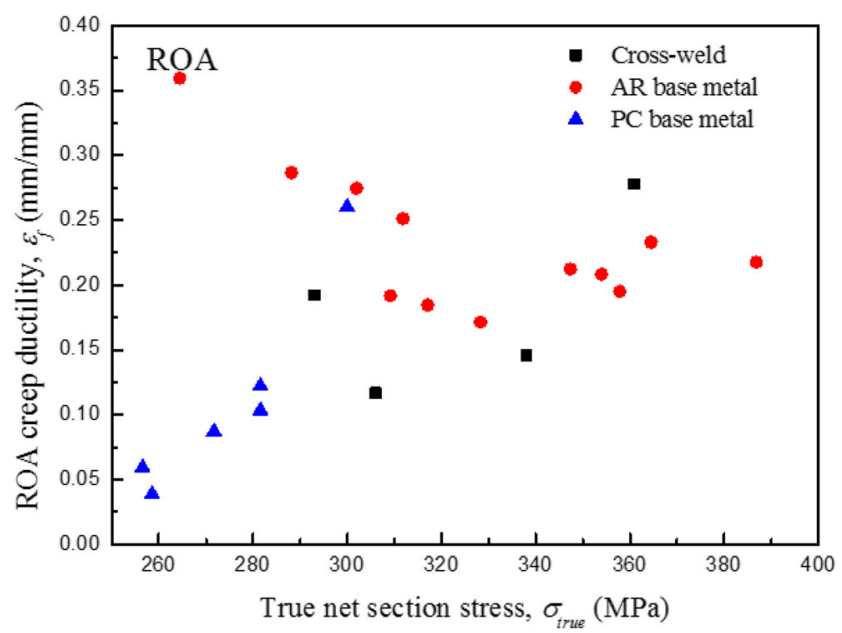

Fig. 13 ROA creep ductility vs. true stress for the XW, AR and PC materials 


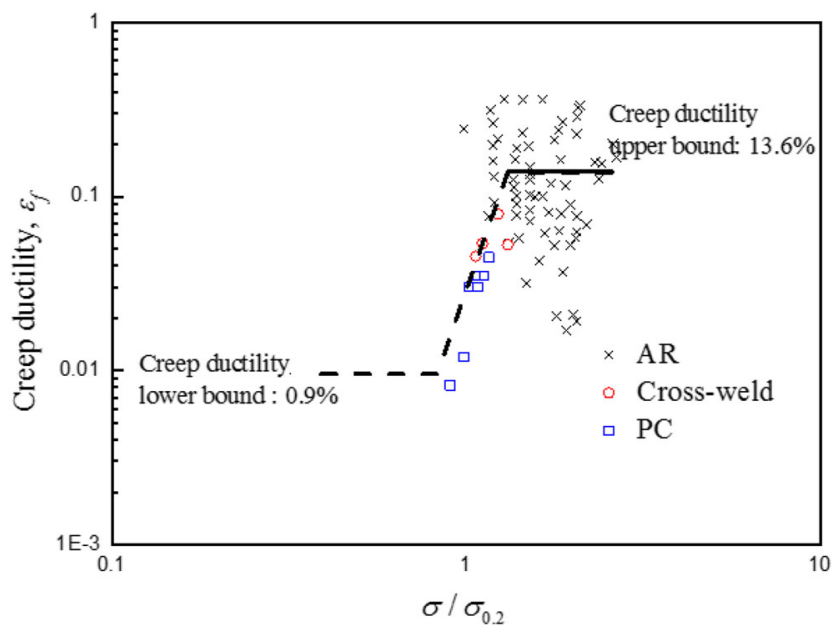

Fig. 14 Comparison of the creep ductility data points obtained from XW, $\mathrm{PC}$ and $\mathrm{AR}$ materials with the estimated normalised trend for the AR material at $550{ }^{\circ} \mathrm{C}$

for a given header material the $\bar{\varepsilon}_{A}^{c}$ is somewhat insensitive to material pre-straining introduced by welding and precompression within the inherent experimental scatter. It can be observed in Fig. 17 that for a given value of stress the rupture time in XW specimens reduces, by around a factor of three, compared to the AR material and the inferred trend for XW specimens is found similar to those of obtained from the PC material extracted from different headers.

The results presented in Figs. 16 and 17 suggest that unlike the AR material state which exhibits noticeable variation from one header component to another, the average creep strain rate and rupture life of the XW material can be estimated in a much simpler and cheaper way by performing tests on the PC material. This is an important and practical conclusion which implies that the pre-conditioning effects in the XW material can be replicated by pre-straining the material without expecting to observe any significant header-to-header variation in the test results. Furthermore, it has been shown in Fig. 14 that when the axial

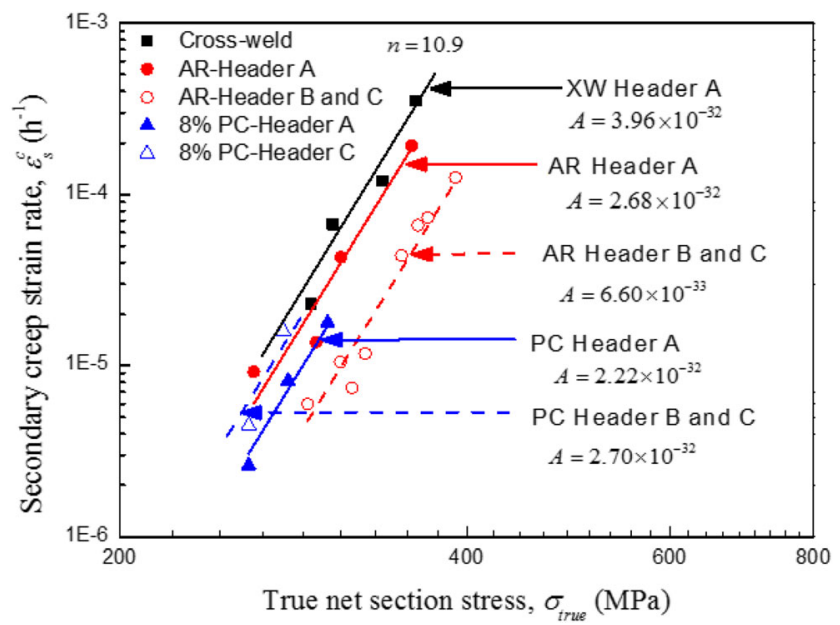

Fig. 15 Comparison of the secondary creep strain rate trends for the XW, $\mathrm{PC}$ and AR specimens

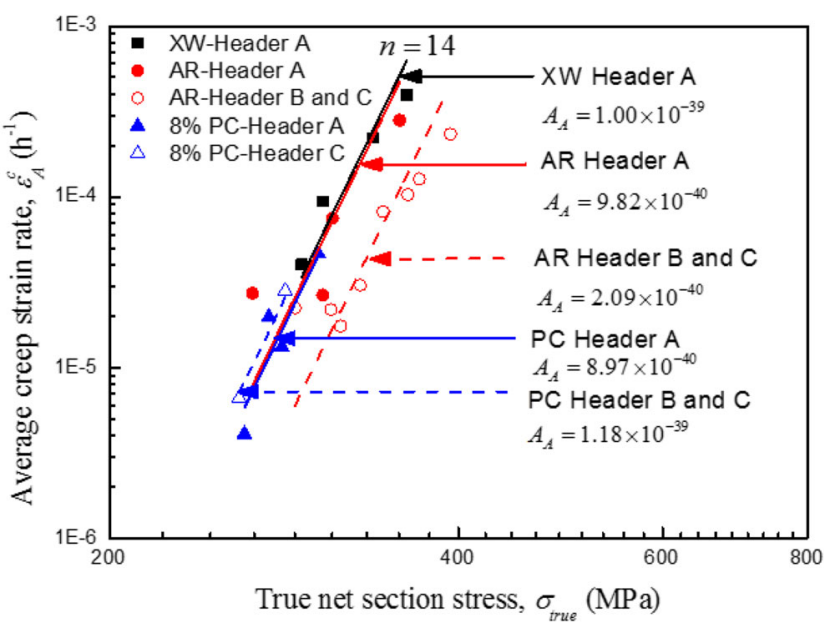

Fig. 16 Comparison of the average creep strain rate trends for the XW, $\mathrm{PC}$ and AR specimens

creep ductility of the XW and PC specimens is correlated with the normalised stress, the data points fall upon the estimated normalised trend which was originally developed for the AR material at $550{ }^{\circ} \mathrm{C}$ in Ref [26]. This may suggest that the longterm creep ductility of the AR and XW materials, particularly in the low stress lower shelf region where the tests take much longer to complete, can be estimated in much shorter timescales by performing tests on the PC specimens.

Knowing that the ex-service steam header used to extract specimens in this study was in operation at high temperature for many years, it is assumed that residual stresses were vastly relaxed and had minor effects on the uniaxial creep deformation and rupture behaviour of the cross-weld specimen tested in this study. In addition, the process of round bar uniaxial creep specimen extraction from the steam header is expected to have released possible remaining residual stresses. Therefore, the observed results on cross-weld specimens are expected to be due to mechanical and microstructural changes induced into the

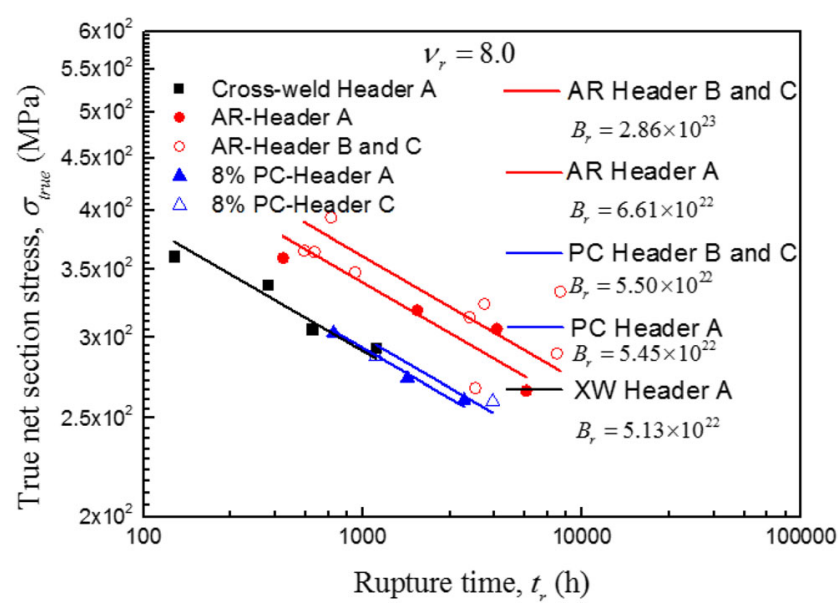

Fig. 17 Comparison of the time to rupture trends for the $\mathrm{XW}, \mathrm{PC}$ and $\mathrm{AR}$ specimens 
material as a result of material pre-conditioning during the welding process as well as in-service aging.

\section{Conclusions}

Experiments were performed on XW specimens extracted from an ex-service steam header to characterise the uniaxial creep properties of a $316 \mathrm{H}$ stainless steel welded component. The results from these tests were compared to those of available on the $\mathrm{AR}$ and PC materials extracted from the same and other steam headers. The results show that the yield stress of the XW material is higher than the base metal both at room temperature and $550{ }^{\circ} \mathrm{C}$, indicating that the material pre-straining has been introduced into the component during the welding process. Moreover, it has been found that the creep ductility in the XW and PC materials can be well described by the estimated normalised trend for the AR material at $550{ }^{\circ} \mathrm{C}$. Therefore, the long-term uniaxial creep ductility of the AR and cross-weld material is comparable to much shorter tests on pre-strained specimens. The uniaxial creep test results have also shown that similar average creep strain rate and rupture time trends could be found in the XW and PC specimens indicating that the creep power-law constants of the XW specimens may be estimated by performing tests on uniformly pre-compressed specimens which are easier and cheaper to manufacture compared to the weld specimens.

\section{Compliance with Ethical Standards}

Ethics Declarations This article does not contain any studies involving animals or human participants performed by any of the authors.

Conflict of Interest The authors declare no competing financial interest.

Open Access This article is licensed under a Creative Commons Attribution 4.0 International License, which permits use, sharing, adaptation, distribution and reproduction in any medium or format, as long as you give appropriate credit to the original author(s) and the source, provide a link to the Creative Commons licence, and indicate if changes were made. The images or other third party material in this article are included in the article's Creative Commons licence, unless indicated otherwise in a credit line to the material. If material is not included in the article's Creative Commons licence and your intended use is not permitted by statutory regulation or exceeds the permitted use, you will need to obtain permission directly from the copyright holder. To view a copy of this licence, visit http://creativecommons.org/licenses/by/4.0/.

\section{References}

1. Dean DW, Gladwin DN (2007) Creep crack growth behaviour of type $316 \mathrm{H}$ steels and proposed modifications to standard testing and analysis methods. Int J Press Vessel Pip 84(6):378-395

2. Vakili-Tahami F, Hayhurst DR (2007) Failure of a welded pressure vessel due to creep: damage initiation, evolution and reheat cracking. Philos Mag 87(28):4383-4419
3. Holt PJ (1996) Harlepool/Heysham I superheater header weld S4: finite element modelling of creep and reheat crack initiation. Nuclear Electric

4. Skelton RP, Goodall IW, Webster GA, Spindler MW (2003) Factors affecting reheat cracking in the HAZ of austenitic steel weldments. Int J Press Vessel Pip 80(7-8):441-451

5. Smith DJ, Bouchard PJ, George D (2000) Measurement and prediction of residual stresses in thick-section steel welds. J Strain Anal Eng Des 35:287-305

6. Hayhurst DR, Vakili-Tahami F, Zhou JQ (2003) Constitutive equations for time independent plasticity and creep of 316 stainless steel at $550{ }^{\circ} \mathrm{C}$. Int J Press Vessel Pip 80(2):97-109

7. Hares EA, Mostafavi M, Bradford R, Truman CE (2018) The effect of creep strain rate on damage accumulation in type $316 \mathrm{H}$ austenitic stainless steel. Int J Press Vessel Pip 168:132-141

8. Wang YQ, Spindler MW, Truman CE, Smith DJ (2016) Critical analysis of the prediction of stress relaxation from forward creep of type $316 \mathrm{H}$ austenitic stainless steel. Mater Des 95:656-668

9. Mamun AA, Moat RJ, Kelleher J, Bouchard PJ (2014) Generation of intergranular strains during high temperature creep fatigue loading of 316H stainless steel. Mater High Temp 31(4):378-382

10. Dey S, Knowles DM, Truman CE (2018) Graded creep deformation properties of $316 \mathrm{H}$ welds and its impact on creep. In: Pressure Vessels and Piping Conference (Vol. 51678, p V06AT06A054). American Society of Mechanical Engineers

11. Sakanashi Y, Gungor S, Forsey AN, Bouchard PJ (2017) Measurement of creep deformation across welds in $316 \mathrm{H}$ stainless steebel using digital image correlation. Exp Mech 57(2):231-244

12. Mamun AA, Simpson C, Erinosho T, Agius D, Reinhard C, Mostafavi M, Knowles D (2019) Effect of plasticity on creep deformation in type 316h stainless steel. In: ASME 2019 Pressure Vessels \& Piping Conference. American Society of Mechanical Engineers Digital Collection

13. Jazaeri H, Bouchard PJ, Hutchings MT, Spindler MW, Mamun AA, Heenan RK (2019) An investigation into creep cavity development in 316H stainless steel. Metals 9(3):318

14. Meng L, Chen W, Yan Y, Kitamura T, Feng M (2019) Modelling of creep and plasticity deformation considering creep damage and kinematic hardening. Eng Fract Mech 218:106582

15. Mehmanparast A, Davies CM, Dean DW, Nikbin K (2013) Material pre-conditioning effects on the creep behaviour of $316 \mathrm{H}$ stainless steel. Int J Press Vessel Pip 108-109(0):88-93

16. Davies CM, Dean DW, Mehmanparast A, Nikbin KM (2010) Compressive pre-strain effects on the creep and crack growth behaviour of $316 \mathrm{H}$ stainless steel. In: Pressure Vessels and Piping Conference (Vol. 49255, pp 323-330)

17. Mehmanparast A, Davies CM, Dean DW, Nikbin KM (2013) The influence of pre-compression on the creep deformation and failure behaviour of type 316H stainless steel. Eng Fract Mech 110(0):52-67

18. Mehmanparast A, Davies CM, Dean DW, Nikbin K (2016) Effects of plastic pre-straining level on the creep deformation, crack initiation and growth behaviour of $316 \mathrm{H}$ stainless steel. Int J Press Vessel Pip 141:1-10

19. Webster GA, Ainsworth RA (2013) High temperature component life assessment. Springer Science \& Business Media, Berlin

20. Anderson TL (2017) Fracture mechanics: fundamentals and applications. CRC press, Boca Raton

21. Aramis User Manual v6.3.0, GOM, Braunschweig, Germany

22. Acar M, Gungor S, Bouchard PJ, Fitzpatrick ME (2011) Effect of prior cold work on the mechanical properties of weldments. Experimental and Applied Mechanics 6:817-826 Springer, New York, NY

23. ASTM (2012) E139-11: standard test methods for conducting creep, creep-rupture, and stress-rupture tests of metallic materials. ASTM Standard, vol. 03, no 01

24. Spindler MW (1997) Creep ductility of type 316 and $316 \mathrm{H}$ austenitic steels between 500 and $700{ }^{\circ} \mathrm{C}$. Nuclear Electric Plc 
25. Bettison A (2001) The influence of constraint on the creep crack growth of $316 \mathrm{H}$ stainless steel. Imperial College London, London

26. Mehmanparast A, Davies CM, Webster GA, Nikbin KM (2014)

Creep crack growth rate predictions in $316 \mathrm{H}$ steel using stress dependent creep ductility. Mater High Temp 31(1):84-94

27. Mehmanparast A (2014) Prediction of creep crack growth behaviour in $316 \mathrm{H}$ stainless steel for a range of specimen geometries. Int J Press Vessel Pip 120:55-65
28. Quintero H, Mehmanparast A (2016) Prediction of creep crack initiation behaviour in $316 \mathrm{H}$ stainless steel using stress dependent creep ductility. Int J Solids Struct 97:101-115

Publisher's Note Springer Nature remains neutral with regard to jurisdictional claims in published maps and institutional affiliations. 